\title{
Genç Futbolcularda Statik ve Dinamik Germe Egzersizlerinin Tekrarlı Sprint Performansına Etkisi
}

\author{
Mehmet Gören KÖSE1 ${ }^{(D)}$, Erdi YILDIRIM² (D) , Ayşe KIN IŞLER ${ }^{1}$ \\ ${ }^{1}$ Hacettepe Üniversitesi Spor Bilimleri Fakültesi, Egzersiz ve Spor Bilimleri Bölümü, ANKARA \\ ${ }^{2}$ Yıldırım Beyazıt Üniversitesi, Sağlık Bilimleri Enstitüsü, ANKARA
}

Araştırma Makalesi

DOI: 10.53434/gbesbd.939426

Öz

Bu çalışmanın amacl; genç futbolcularda statik ve dinamik germe egzersizlerinin tekrarlı sprint performansına etkisini incelemektir. Bu amaçla, çalıșmaya amatör bir futbol takımının alt yapı takımlarında yer alan 17 genç futbolcu (yaş: $16.47 \pm 0.62$ yıl, boy: $174.91 \pm 6.54 \mathrm{~cm}$, vücut ağırlığı: $63.08 \pm 9.74 \mathrm{~kg}$, vücutyağ \%: 6.41 $\pm 4.59 \%$ ) katılmıștır. Genç futbolculara iki ayrı günde statik germe (SG) veya dinamik germe (DG) egzersizleri yaptırıldıktan sonra 5 dakika pasif dinlenmenin ardindan $6 \times 30 \mathrm{~m}$ Tekrarlı Sprint Testi (TST) uygulanmıştır. TST sırasında en iyi sprint zamanı (EISZ), ortalama sprint zamanı (OSZ), toplam sprint zamanı (TSZ) ve performans düşüş yüzdesi (PDY) değerleri belirlenmiştir. Isınma ve TST sırasındaki kalp atım hızı (KAH) ölçümleri de değerlendirmeye alınmıştır. SG ve DG egzersizlerinin TST performansına etkisi bağımlı gruplarda t-testi ile belirlenmiștir. Bağımlı gruplarda t-testi sonuçları, SG ve DG egzersizleri sonrasında uygulanan TST sonucunda EISZ, OSZ, TSZ ve PDY değerleri arasında istatistiksel olarak anlamlı bir fark olmadığını göstermiștir ( $p>0.05)$. Germe egzersizleri sirasındaki KAH değerleri incelendiğinde, DG-KAH değerleri SG'den anlamlı şekilde yüksek [t(16)=-4,234; $p<0.05]$, ancak TST sirasinda ölçülen KAH değerleri benzer bulunmuştur ( $p>0.05)$. Bu çalışmanın sonuçları TST öncesi uygulanan SG ve DG egzersizlerinin fizyolojik etkilerinin farklı olduğunu ancak bu farklılığın tekrarlı sprint performans çıktıları üzerinde etkili olmadığını göstermiștir.

Anahtar sözcükler: Isınma, Aralıklı sprint, Genç sporcular 


\title{
The Effect of Static and Dynamic Stretching Exercises on Repeated Sprint Performance in Young Football Players
}

\begin{abstract}
The aim of this study was to examine the effects of static and dynamic stretching exercises on repeated sprint performance in young football players. For this purpose, the study data were collected from 17 young football players from the youth teams of an amateur football team in Ankara. Football players participated in static stretching (SS) or dynamic stretching (DS) exercises on two different days randomly followed by a 6x30m Repeated Sprint Test (RST) applied with a 30-second rest interval after a 5-minute passive recovery. During the RST, best sprint time (BST), average sprint time (AST), total sprint time (TST) and percentage of performance decrement (PPD) were determined. Heart rate (HR) measurements during the warm-up and RST were also evaluated. The effect of SG and DG exercises on RST performance was determined by paired samples $t$-test. The $t$-test results showed that there was no significant difference between BST, AST, TST, and PPD values after SS and DS exercises ( $p>0.05)$. When the HR values during stretching exercises were examined, DS-HR values were found to be significantly higher than the SS-HR, however the HR values during the RST were similar. The results of this study indicated that although the physiological effects of SS and DS exercises before RST were different, this difference did not affect the RST performance outputs.
\end{abstract}

Keywords: Warm-up, Intermittent sprint, Young athletes

\section{Giriş}

Isınma vücut sıcaklığını arttırmak, kan akışını hızlandırmak ve vücudu egzersize hazırlamak için tasarlanmış hareketler bütünü olarak tanımlanmaktadır. Her türlü sportif etkinlikte ısınma ile buna bağlı olarak germe egzersizleri yaygın olarak kullanılmakta ve gerek antrenmanlarda gerekse yarışmalarda bu çalışmalardan sonra antrenmanın ana bölümüne geçilmektedir (Fletcher ve Jones, 2004). Sporcular ve antrenörler, genellikle yalnızca kişisel tercihlerine dayanan birçok farklı germe türü kullanmaktadır, ancak en uygun germe türü veya germe hareket sayısı net bir şekilde belirlenmemiştir. Bilindiği üzere balistik germe, proprioseptif nöromüsküler fasilitasyon (PNF), statik germe (SG) ve dinamik germe (DG) gibi çeşitli germe çeşitleri bulunmakta ve yaygın olarak kullanılmaktadır (Sekir, Arabaci, Akova ve Kadagan, 2010).

Spor performansından önce SG yaygın olarak uygulanmakta olan bir germe çeşididir ve genellikle ısınmanın temel bir bileșeni olarak kabul edilmektedir. SG kası hareket genişliğinin sonuna kadar götürmeyi ve bir süre orada sabit olarak kalmayı içerir. SG, yaralanma riskini ve tipik olarak yorucu aktiviteden sonra ortaya çıkan kas ağrısı derecesini azaltmak için de kullanılmaktadır. Ek olarak, eklem hareket genişliğini iyileştirmek, esnekliği artırmak ve potansiyel olarak atletik performansa fayda sağlamak için de SG düzenli olarak kullanılan bir germe çeşididir (Sim, Dawson, Guelfi, Wallman ve Young, 2009). Ancak son dönemde yapılan çalışmalar SG'nin tekrarlı sprint testi (TST) en iyi sprint zamanı (EİSZ) performansında farklılığa neden olmadığını (Wong, Chaouachi, Lau ve Behm, 2011), 10, 20 ve 50m sprint performansını olumsuz etkilediğini (Alemdaroğlu ve Koz, 2009), sıçrama performansında ise düşüșe neden olduğunu (Bradley, Olsen ve Portas, 2007; Fletcher ve Anness, 2007) göstermiştir. 
Her eklem için aktif hareket genişliği boyunca kontrollü hareketi içeren DG egzersiz protokollerinin çeşitli varyasyonları bulunmasına rağmen, çoğu sürekli ve ritmik hareketleri içerir (Fletcher, 2010; Manoel, Harris-Love, Danoff ve Miller, 2008). Araştırmacıların DG egzersizlerinin esnekliği geliştirme konusuna kaygıyla yaklaşmasına rağmen (Shrier ve Gossal, 2000), düşük şiddetten orta şiddete doğru yapılan DG hareketlerinin hem yetişkinlerde hem de çocuklarda SG egzersizlerine alternatif olabileceğini ileri sürülmektedir (Faigenbaum, Bellucci, Bernieri, Bakker ve Hoorens, 2005; Herbert ve Gabriel, 2002; Shrier ve Gossal, 2000). Bu tür germe egzersizlerinin dikey sıçrama (Young ve Behm, 2003) performansı iyileştirdiği ve bacak kuvvetini (Yamaguchi, Ishii, Yamanaka ve Yasuda, 2007) artırdığı gözlemlenmiştir. Ancak, bu bulguların aksine Nelson ve Kokkonen (2001), DG egzersizinin maksimal diz fleksiyon ve ekstansiyon kuvvetini düşürdügünü belirtmişlerdir. Bu nedenle, DG'nin kas performansı üzerindeki etkisi konusunda net bir fikir birliğine ulaşılamamıștır.

Kısa süreli ve kısa toparlanma aralıklarıyla uygulanan sprint koşularını tekrarlı uygulayabilme yeteneği, literatürde tekrarlı sprint performansı olarak adlandırılmaktadır (Mujika, Spencer, Santisteban, Goiriena ve Bishop, 2009). Tekrarlı sprint performansı, özellikle takım sporlarında önemli bir performans bileșeni olarak kabul edilmektedir (Gharbi, Dardouri, Haj-Sassi, Chamari ve Souissi, 2015). Örneğin futbolcular müsabakalar sırasında kısa ve uzun mesafe sprintleri oldukça fazla sayıda gerçekleștirmektedir ve bu sprintlerin tekrarlı bir şeklide gerçekleştirilmesi futbol için oldukça önemli bir performans belirleyicisidir (Mujika ve diğ., 2009). Tekrarlı sprint performansının profesyonel sporcularda lige seviyesine (Impellizzeri ve diğ., 2008), genç futbolcularda ise yaşa (Mujika ve diğ., 2009; Özdemir, Yilmaz ve Kin Isler, 2014) göre farklılık göstermesi oyuncu seçimi ve değerlendirilmesinde kullanılabileceğinin açık bir göstergesidir. Mujika ve diğerleri (2009) genç futbolcularda tekrarlı sprint performansının 11-15 yaş aralığında gelişerek arttığını rapor etmişler, ancak 15-18 yaş aralığında istatistiksel olarak bir artış gözlemleyememişlerdir. Benzer şekilde Özdemir ve diğerleri (2014) ise, 14-16 yaş genç futbolcularda tekrarlı sprint performansını inceledikleri çalışmalarında, yaş arttıkça tekrarlı sprint performansının EİSZ ve toplam sprint zamanı (TSZ) gibi bileșenlerinin arttığını ve bu artışın kronolojik yaş ile birlikte fiziksel özelliklerdeki değişimden kaynaklanabileceğini belirtmişlerdir.

Futbol, tekrarlanan yüksek şiddetli kısa süreli motor yetilerden kaynaklı anaerobik enerji sisteminin kullanıldığı (Eniseler, Çamlıyer ve Göde, 1996) ancak müsabaka sırasında çok sayıda düşük şiddetli aktivitenin (durma, yürüme vb.) de yer aldığı aerobik temelli bir takım sporudur (Mohr, Krustrup ve Bangsbo, 2003). Ayrıca hız, güç, kuvvet ve çeviklik gibi motor bileșenlerinde müsabaka sırasında öneme sahip olduğu belirtilmiștir (Fletcher ve Monte-Colombo, 2010). Bir futbol müsabakası sırasında çok sayıda negatif ve pozitif ivmelenmeler içeren tekrarlı sprint performansı sergilenmektedir. Müsabaka sırasında toplam kat edilen mesafenin \%1-11'ini sprint aktiviteleri oluşmaktadır. Müsabaka analizleri bu sprintlerin yaklaşık 90 sn'de bir tekrarlandığını ve ortalama 2-4 sn. süreyle devam ettiğini göstermektedir (Stølen, Chamari, Castagna ve Wisløff, 2005). Uygun bir ısınma ve germe egzersizinin, sürat (Little ve Williams, 2006), çeviklik (Amiri-Khorasani, 
Sahebozamani, Tabrizi ve Yusof, 2010) yön değiștirmeli tekrarlı sprint (Little ve Williams, 2006), doğrusal tekrarlı sprint (Zmijewski ve diğ., 2020), sıçrama (Young ve Behm, 2003) gibi takım sporları sırasında kullanılan birçok motorik özellik üzerinde etkili olduğu belirtilmiștir. İyi bir ısınma protokolünün sporcuların müsabaka performansına katkı sağlayabileceği ve yaralanma riskini de azaltabileceği düşünülmektedir (Behm, Blazevich, Kay ve McHugh, 2016; Little ve Williams, 2006).

Literatürde egzersiz öncesi uygulanan germe egzersizlerinin performans parametrelerine akut etkisi üzerine çelişkili sonuçlar rapor edilmiştir (Fletcher ve Anness, 2007; Fletcher ve Monte-Colombo, 2010; Marinho, Gil, Marques, Barbosa ve Neiva, 2017; Nelson ve Kokkonen, 2001; Sim ve diğ., 2009; Turki-Belkhiria ve diğ., 2014; Yamaguchi ve diğ., 2007; Young ve Behm, 2003). SG ve DG egzersizleri ile ilgili yapılan çalışmaların çoğunlukla yetişkin sporcular üzerinde gerçekleştirilmesi, genç futbolcular üzerinde yapılan germe egzersizlerinin TST üzerine etkisini inceleyen çalışmaların sınırlılığı bu çalışmanın temelini oluşturmuştur. Bu amaçla çalışmada genç futbolcularda SG ve DG egzersizlerinin TST performansı üzerine etkisi incelenmiştir.

\section{Yöntem}

$\mathrm{Bu}$ çalışmaya Ankara ili amatör bir futbol kulübünde yer alan, 15-17 yaş aralığında 17 futbolcu gönüllü olarak katılmıştır. Katılımcıların fiziksel özellikleri Tablo 1'de verilmiştir. Araştıma için Hacettepe Üniversitesi Girişimsel Olmayan Klinik Etik Kurulu'ndan 15.12.2020 tarih ve 16969557-09 sayılı karar ile etik onay alınmıştır.

Tablo 1: Katılımcıların ait fiziksel özellikler

\begin{tabular}{lc}
\hline Değişkenler & $\overline{\mathbf{X}}$-SS \\
\hline Yaş (yıl) & $16,47 \pm 0,62$ \\
Boy Uzunluğu (cm) & $174,91 \pm 6,54$ \\
Vücut Ağırlı̆̆ı (kg) & $63,08 \pm 9,74$ \\
Yağ Yüzdesi (\%) & $6,41 \pm 4,59$ \\
\hline
\end{tabular}

\section{Verilerin Toplanması}

Katılımcılardan testlerden 24 saat önce fiziksel aktivite yapmamaları, alkol ve kafein içeren içecekler tüketmemeleri istenmiştir. TST öncesi öncelikle katılımcılara ait boy uzunluğu portatif stadiometre (Holtain, İngiltere) ile vücut ağırlı̆̆ ölçümleri elektronik baskül (Tanita TBF 401 A, Japonya), vücut yağ yüzdesi ölçümleri ise biyoelektrik impedans analizörü ile (Tanita TBF 401 A, Japonya) gerçekleştirilmiştir.

Bu ölçümlerin ardından ısınma ve TST sırasında KAH cevaplarının takip edilebilmesi için katılımcılara telemetrik KAH monitörü (Polar 810i, Kempele, Finlandiya) takılmış ve veriler 1 sn aralıklarla kaydedilmiştir. Isınma protokolleri 5 dakikalık düşük şiddetli ısınma koşusu sonrasında rastgele sırayla belirlenen germe protokolü (SG veya DG) şeklinde 
uygulanmıştır (Şekil 1). Germe protokolünün sonrasında 5 dakikalık pasif toparlanma verilmiş ve ardından katılımcılar TST'ne katılmışlardır. TST'leri futbol takımına ait suni çim antrenman sahasında, sirkadiyen ritmin fizyolojik etkileri göz önüne alınarak günün aynı saat diliminde (17:00-20:00), TST sonrası yorgunluk etkisinin ortadan kaldırılabilmesi için 48 saat arayla ve rastgele sırayla gerçekleştirilmiştir.

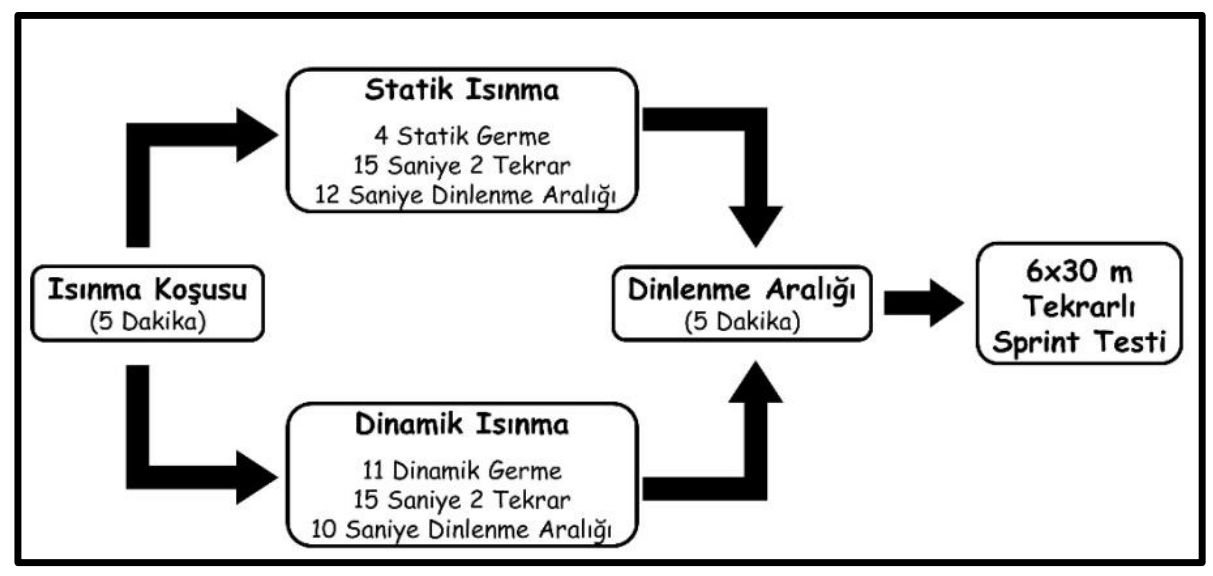

Şekil 1. Araştırma deseni

\section{Isınma Protokolleri}

Katılımcılara TST’i öncesinde rastgele sırayla SG ve DG protokolleri uygulanmıștır.

\section{Statik germe protokolü}

$\mathrm{Bu}$ protokol 4 alt ekstremite kasına yönelik düzenlenmiş SG hareketinden oluşmaktadır. SG uygulamaları yavaşça (aktif germe), kişi duyarlılık noktasına ulaştığı noktada (ağrı eşiğinde) 15 saniye süreyle 2 kez uygulanmış ve tekrarlar arasında 12 saniye dinleme aralığı verilmiştir (Thompsen, Kackley, Palumbo ve Faigenbaum, 2007).

SG egzersizleri yaklaşık 3:45 dakika sürmüştür ve uygulanan hareketler aşağıda belirtilmiştir.

1. Kalf Gerdirmesi (Calf Stretch)

2. Bacağı Göğüse Çekerek Gerdirme (Knee-to-Chest)

3. Hamstring Gerdirmesi (Hamstring Stretch)

4. Quadriceps Gerdirmesi (Quadriceps Stretch)

\section{Dinamik Germe Protokolü}

Bu protokol 11 DG egzersizinden oluşmaktadır. Katılımcılar her bir DG egzersizini 15 sn boyunca, gittikçe artan şiddet ile uygulamış ve 10 saniye dinlendikten sonra aynı egzersizi tekrar başlangıç noktasına kadar tekrarlamışlardır (Thompsen ve diğ., 2007). 
DG egzersizleri yaklaşı 9:15 dakika sürmüştür ve uygulanan hareketler aşağıda belirtilmiştir.

1. Diz Çekerek Yürüme (High Knee Walk)

2. İleri Doğru Bacakları Kaldırarak Yürüme (Forward Gate Swings)

3. Geri Geri Bacakları Kaldırarak Yürüme (Backward Gate Swings)

4. Eller Yukarı Kaldırılarak İleri Doğru Yürüme (Overhead Lunge Walk)

5. Dizler Bükülmeden Öne Doğru Yürüyüş (Straight Leg Walk)

6. Asker Yürüyüşü (Toy Soldier Walk)

7. Bacak Açarak Yan Yan Yürüme (Lateral Lunge Walk)

8. Dizi Kaldırarak İleri Doğru Sıçrama (High Knee Skip)

9. Dizi Kaldırarak İleri Doğru Koşu (High Knee Run)

10. Hareketli Topuk Vuruşu (Heel Kick)

11. İleri Doğru Sıçrama (Power Skip)

Tekrarlı Sprint Testi Performansının Belirlenmesi

TST, Mujika ve diğerlerinin (2009) geliștirdiği test protokolüne göre 30 sn pasif dinlenme aralığıyla 6 x 30m doğrusal sprint koşusu olarak uygulanmıştır. Testte fotosel kapıları (Fusion Sport, Avusturalya) başlangıç ve bitiş noktalarına yerleştirilmiş ve 6 tekrar 0-30m skor zamanları saniye cinsinden kaydedilmiştir. Test sonunda aşağıdaki parametreler hesaplanmıştır;

En iyi Sprint Zamanı (EISSZ): 6 tekrarlı sprintte koşulan en iyi süre dikkate alınmıştır.

Ortalama Sprint Zamanı (OSZ): 6 tekrarın sprint zamanı ortalaması hesaplanmıştır.

Toplam Sprint Zamanı (TSZ): 6 tekrarın toplam sprint zamanı hesaplanmıştır.

Performans Düşüş Yüzdesi (PDY): PDY değerleri Wadley ve Le Rossignol'ye (1998) ait aşağıdaki formül kullanılarak hesaplanmıştır

$$
\text { PDY } \%=\frac{\text { Toplam Sprint Zamanı x } 100}{-100}
$$

En İyi Sprint Zamanı x Tekrar Sayısı

\section{Verilerin Analizi}

Çalışmaya katılan tüm sporculardan toplanan verilere ait ortalama ve standart sapma değerleri hesaplanmış ardından verilerin normal dağılıp dağılmadığına Shapiro-Wilk testi kullanılarak bakılmıştır. Verilerin normal dağılım gösterdiği belirlendikten sonra SG ve DG egzersizlerinin TST parametrelerinden EİSZ, TSZ, OSZ ve PDY'ne etkisinin belirlenmesi için bağımlı gruplarla t-testi kullanılmıştır. İstatistiksel işlemler için Windows SPSS 22.0 programı kullanılmış ve tüm istatistiksel ișlemlerde anlamlılık düzeyi $\mathrm{p}<0.05$ olarak kabul edilmiştir. 


\section{Bulgular}

Katılımcılara ait ısınma ve TST sonucu elde edilen KAH yanıtlarına ilişkin t-testi bulguları

Tablo 2'de verilmiştir.

Tablo 2: Katılımclların germe egzersizi ve TST sırasındaki kalp atım hızı cevapları

\begin{tabular}{lcccc}
\hline & Statik & Dinamik & $\mathbf{p}$ & t \\
\hline $\begin{array}{l}\text { Germe KAH } \\
\text { (atım/dk) }\end{array}$ & $129,82 \pm 25,31$ & $157,19 \pm 16,50$ & $0,001^{*}$ & $-4,234$ \\
$\begin{array}{l}\text { TST KAH } \\
\text { (atım/dk) }\end{array}$ & $173,06 \pm 12,41$ & $176,40 \pm 9,96$ & 0,354 & $-1,112$ \\
\hline${ }^{*} \mathrm{p}<0.05$ & & & &
\end{tabular}

Tablo 2 incelendiğinde TST öncesi katılımcılara ait DG egzersizi KAH cevapları SG KAH cevaplarından anlamlı düzeyde yüksek olduğu görülürken [t(16)=4.308; $\mathrm{p}<0.05]$, TST sırasında ölçülen KAH değerleri arasında ise anlamlı fark olmadığı görülmüştür ( $p>0.05)$.

Katılımcların TST sonucu elde edilen EİSZ, OSZ, TSZ ve PDY yanıtlarına ilișkin t-testi bulguları Tablo 3'te sunulmuştur.

Tablo 3: Farklı germe egzersizleri sonrası katılımcılara ait TST sonuçlarına ilişkin bulgular

\begin{tabular}{lcccc}
\hline & Statik & Dinamik & p & t \\
\hline EİSZ (sn) & $4,41 \pm 0,21$ & $4,40 \pm 0,24$ & 0,787 &, 274 \\
OSZ (sn) & $4,54 \pm 0,20$ & $4,54 \pm 0,24$ & 0,882 &,- 151 \\
TSZ (sn) & $27,21 \pm 1,22$ & $27,24 \pm 1,46$ & 0,837 &,- 209 \\
PDY (\%) & $2,98 \pm 1,27$ & $3,32 \pm 1,77$ & 0,438 &,- 795 \\
\hline
\end{tabular}

Tablo 3 incelendiğinde, farkl germe protokollerinin ardından uygulanan TST performansında EISZ, OSZ, TSZ ve PDY değerleri arasında anlamlı farklılık olmadığ görülmektedir ( $\mathrm{p}>0.05)$.

\section{Tartışma ve Sonuç}

Farklı germe egzersizleri sonrası uygulanan TST performansının değerlendirilmesi amacıyla gerçekleştirilen bu çalışma sonucunda elde edilen bulgular TST öncesi DG-KAH değerlerinin SG-KAH'ye göre daha yüksek olduğunu göstermektedir. Bu bulgu beklenen bir sonuçtur ve literatürdeki çalışmalarda desteklenmektedir. Örneğin farklı germe protokollerinin kuvvet performansına etkisinin incelendiği bir çalışmada ısınma KAH değerlerinde anlamlı fark rapor edilmiştir. En yüksek ısınma KAH değerlerinin DG protokolüne, en düşük ısınma KAH değerlerinin ise SG protokolüne ait olduğu belirlenmiştir (Kafkas ve diğ., 2018). Fletcher ve diğerleri'nin (2010) 27 futbolcu üzerinde 3 farklı ısınma protokolünün (Aktif ısınma, SG, DG) farklı motorik özelliklere etkisini 
inceledikleri çalışmalarında, DG protokolü KAH cevapları hem aktif ısınma hem de SG protokolüne göre daha yüksek bulunmuștur. DG hareketlerinin metronom yardımıyla farklı hızlarda gerçekleștirildiği bir diğer çalışmada ise (50 vuruş/dakika, 100 vuruş/dakika) DG egzersizi sırasında hız arttıç̧a KAH cevaplarının da buna paralel olarak artış gösterdiği gözlemlenmiştir. Buna ek olarak farklı DG egzersizleri sırasında ölçülen KAH değerlerinin de germe egzersizi yapmayan gruba (kontrol) göre daha yüksek olduğu görülmüştür (Fletcher, 2010). DG egzersizleri SG egzersizlerine göre daha yüksek şiddette uygulandığı için vücut sıcaklığında daha fazla artışa neden olmaktadır (Fletcher, 2010) ve bu artış KAH cevaplarına da yansımaktadır. Benzer şekilde bu çalışmada DG egzersizleri hem daha fazla hareket sayısına sahiptir ve hem de SG egzersizlerine göre daha yüksek şiddette uygulanmıştır. Bu şiddet artışı kaslarda daha fazla $\mathrm{O}_{2}$ ihtiyacına neden olurken, kardiyovasküler sistem bu ihtiyacı yüksek KAH cevaplarıyla karşılamıştır. Sonuç olarak DG egzersizleri daha yüksek KAH'a neden olmuştur.

Germe KAH cevaplarının aksine TST'leri sırasında ölçülen KAH değerleri arasında anlamlı fark olmadığı belirlenmiştir. Bu bulgu uygulanan her iki germe protokolünün de TST performansı sırasında benzer fizyolojik etkilere neden olduğunu göstermektedir ve literatürdeki bazı çalışmalarla desteklenmektedir. Marinho ve diğerleri (2017) germe egzersizi yapmayan kontrol grubu ile SG ve DG egzersizi yapan katılımcı grubunun 60 metrelik sürat performansını karşılaştırmışlardır. Sürat testi sırasında kontrol grubunun KAH yanıtları SG ve DG grubuna göre yüksek bulunmuş, ancak SG ve DG egzersizi yapan grup bu çalışmada olduğu gibi benzer KAH cevapları göstermiştir. 3 farklı germe egzersizi ve kombinasyonu (DG, DG+SG, SG+DG) sonrası uygulanan TST sırasında farklı germe egzersizlerinin KAH cevaplarını farklılaştırmadığı da gözlemlenmiștir (Sim ve diğerleri, 2009). TST kısa dinlenme aralıklarıyla maksimum hızda uygulanan süratte dayanıklılık performansının değerlendirildiği bir testtir. Test sporcu üzerinde yüksek fizyolojik yüklenmeye neden olmakta ve kardiyovasküler sistemin sınırlarını zorlamaktadır. Bilindiği üzere, organizma yüksek şiddetli sprintler sırasında enerji harcamasının nerdeyse tamamını ATP-PCr depolarından karşılamakta ve bu durum devam eden egzersizle birlikte $\mathrm{O}_{2}$ açıı̆ına neden olmaktadır (Gaitanos, Williams, Boobis ve Brooks, 1993). Bu doğrultuda bu çalışmada TST sırasında oluşan $\mathrm{O}_{2}$ borcunun yerine konulması için KAH yanıtları maksimum atım noktasına ulaşmasına ve dolayısıyla farklı germe egzersizi protokollerinin KAH üzerine etkisinin sınırlanmasına neden olmuş olabilir.

$\mathrm{Bu}$ çalışmanın bulguları farklı germe egzersizleri sonrasında uygulanan TST sonuçlarına göre EİSZ değerleri arasında anlamlı farklılık olmadığını göstermiştir. EİSZ patlayıcı kuvvet ve sürat performansıyla ilişkili bir parametredir (Newman, Tarpenning ve Marino, 2004). Uygulanan germe protokollerinin bu parametreler üzerine etkisini inceleyen birçok çalışma bulunmaktadır ve bu çalışmalarda germe egzersizinin patlayıcı kuvvet ve sürat performansına etkisi net değildir (Fletcher, 2010; Fletcher ve MonteColombo, 2010; Kokkonen, Nelson ve Cornwell, 1998). Farklı SG protokolleri ile DG'nin tekrarlı sprint ve çeviklik performansı üzerindeki etkisinin incelendiği bir çalışmada uygulanan 3 farklı germe protokolünün EISSZ performansını etkilemediği rapor edilmiştir (Wong ve diğ., 2011). 8 haftalık kronik etkinin değerlendirildiği bir başka çalışmada 2 farklı 
DG protokolü ve germe egzersizi yapmayan (kontrol) grup üzerinde uygulanan TST performans parametrelerinden EİSZ bulguları hem kontrol grubuyla hem de ön test son test sonuçlarında anlamlı farklılık göstermemiştir (Turki-Belkhiria ve diğ., 2014). Sim ve diğerleri (2009) hem DG'nin hem de DG ve SG'nin farklı sirayla uygulanmasının TST performans parametreleri üzerindeki etkilerini incelemişlerdir. Çalışma sonucunda farklı germe protokollerinin EİSZ performansını etkilemediği rapor edilmiştir. Bilindiği gibi, EİSZ tekrarlar sırasında tek seferde uygulanan en iyi sprint süresini temsil etmektedir ve sürat performansıyla doğrudan ilişkilidir (Pyne, Saunders, Montgomery, Hewitt ve Sheehan, 2008). Yapılan çalışmalar da farklı germe egzersizlerinin sürat performansında düşüşe neden olabileceğini göstermektedir (Marinho ve diğ., 2017). Uygulanan her iki germe protokolü de sürat performansını etkilememiş veya düşüşe neden olmuş ve EİSZ performansını olumsuz etkilemiş olabilir. Bu düşüş protokoller arası EİSZ değerlerinin farklılaşmamasının nedeni olarak gösterilebilir.

TST'lerine ait OSZ ve TSZ değerleri germe protokollerine göre farklılık göstermemiştir. Literatürde germe egzersizleri ve OSZ ve TST ilişkisini inceleyen çalışmalarda farklı sonuçlar elde edilmiştir. Örneğin kadın hentbolcularda yaplan bir çalışmada SG ve DG protokollerinin bisiklet ergometresi üzerinde uygulanan TST performansına etkisi incelenmiştir. DG egzersizi ortalama güç çıktısı kontrol grubuna göre daha yüksek, SG egzersizi ise kontrol grubuna göre daha düşük değerler göstermiştir (Zmijewski ve diğ., 2020). 13 erkek takım sporcusu üzerinde gerçekleştirilen TST testi sonuçları ise farklı germe protokollerinin TSZ değerlerini farklılaştırmadığını göstermiștir (Sim ve diğ., 2009). Futbolcular üzerinde yapılan bir başka çalışmada da uzun süreli uygulanan DG egzersizi kontrol grubuyla (germe egzersizi yapmayan) karşılaştırıldığında TSZ üzerine etkisi anlamlı bulunmamıştır (Turki-Belkhiria ve diğ., 2014). Yine bir başka çalışmada futbolcular üzerinde gerçekleştirilen üç farklı ısınma protokolünün (Isınma, Isınma+SG, Isınma+DG) TST performansı üzerine etkisi incelenmiştir. Sadece ısınma ve ısınma+ DG uygulayan grupların OSZ değerleri benzer bulunurken, bunun aksine her iki grup OSZ değerleri ısınma+SG uygulayan gruba göre daha iyi sonuç göstetmiş̦tir (Taylor, Weston ve Portas, 2013). Germe egzersizi hem vücut ısısını arttırmak hem de tendon ve kasları performansa hazırlamak amacıyla gerçekleştirilmektedir. Uygulanan 2 farklı germe egzersizi aynı amaca yönelik olsa da uygulanma şekilleri ve motorik özellikler üzerindeki etkilerinin farklılaştığı yapılan çalışmalarda görülmektedir (Fletcher ve Monte-Colombo, 2010; Marinho ve diğ., 2017; Taylor ve diğ., 2013; Turki-Belkhiria ve diğ., 2014; Zmijewski ve diğ., 2020). Isınmanın performans üzerindeki etkileri vücut sıcaklığının yükselmesi, ısınmanın şiddeti ve süresi, aynı zamanda egzersiz türü gibi çeşitli faktörle göre farklılık göstermektedir (Bishop, 2003). Planlanan germe egzersizinin içeriği branşa veya gerçekleştirilecek performansın yapısına uygun olursa germe egzersizinden pozitif etki sağlanabilmektedir. $\mathrm{Bu}$ çalışmada futbol branşına uygun SG ve DG protokolleri uygulanmamış olabilir ve TSZ ile OSZ değerleri germe protokollerine göre anlamlı farklılık göstermemiş olabilir.

$\mathrm{Bu}$ çalışmada iki farklı germe egzersizinin TST performans parametrelerinden PDY üzerine etkisi benzerdir. PDY yüksek şiddetli egzersizler sonrasında oluşan yorgunluğun 
performansa yansıması olarak gösterilmektedir (Özdemir ve diğ., 2014). Bu bulgu uygulanan germe egzersizlerin sporcular üzerinde yorgunluğu uzaklaştırmada benzer etkiyi gösterdiğini göstermektedir. Sim ve diğerleri (2009) hem DG'nin hem de farklı sirayla uygulanan DG ve SG'nin TST performans parametreleri üzerindeki etkilerini incelemiş̧lerdir. Çalışma sonucunda PDY değerlerinde SG üzerine uygulanan DG egzersizi diğer protokollerden 1. sette anlamlı farklılık göstermiştir fakat 3 set ortalama değerleri dikkate alındığında anlamlılık ortadan kalmıştır. 8 hafta uygulanan DG egzersizi protokolünün TST ön test son test değerlendirmesinde PDY'sini farklılaştırmadığı, aynı zamanda kontrol grubuyla da benzer skorlar gösterdiği gözlemlenmiștir (Turki-Belkhiria ve diğ., 2014). Germe egzersizleri arasında PDY'sinin benzerlik göstermesi futbolcuların TST sırasında yorgunluk seviyelerinin de farklı germe egzersizlerinden etkilenmediğini göstermektedir.

Genç futbolcular üzerinde uygulanan SG ve DG egzersizleri sırasında farklı fizyolojik yanıtlar gözlemlense de bu farklılık germe egzersizleri sonrası uygulanan TST fizyolojik ve performans verilerine yansımamıştır. Bu çalışma sonucunda, TST öncesi uygulanacak SG veya DG egzersizlerinin performansı değiştirmediği ve her iki germe egzersizi yönteminin de kullanılabileceği söylenebilir.

\title{
Yazar notu:
}

Bu çalışma 2016 yllında 9. Spor Bilimleri Öğrenci Kongresi'nde sözel bildiri olarak sunulmuştur.

\author{
Yazıșma Adresi (Corresponding Address): \\ Prof. Dr. Ayșe KIN ISŞLR \\ Hacettepe Üniversitesi Spor Bilimleri Fakültesi, Egzersiz ve Spor Bilimleri Bölümü \\ 06800, Beytepe/ANKARA \\ ORCID: https://orcid.org/0000-0001-9651-2067 \\ E-posta: ayse.kinisler@hacettepe.edu.tr
}




\section{Kaynaklar}

1. Alemdaroğlu, U. ve Koz, M. (2009). The acute effect of static, ballistic, and propreceptive neuromuscular facilitation stertching on sprint performance. Paper presented at the $6^{\text {th }}$ European Sport Medicine Congress, Antalya.

2. Amiri-Khorasani, M., Sahebozamani, M., Tabrizi, K. G. ve Yusof, A. B. (2010). Acute effect of different stretching methods on Illinois agility test in soccer players. The Journal of Strength \& Conditioning Research, 24(10), 2698-2704.

3. Behm, D. G., Blazevich, A. J., Kay, A. D. ve McHugh, M. (2016). Acute effects of muscle stretching on physical performance, range of motion, and injury incidence in healthy active individuals: a systematic review. Applied Physiology, Nutrition, And Metabolism, 41(1), 1-11.

4. Bishop, D. (2003). Warm up I. Sports Medicine, 33(6), 439-454.

5. Bradley, P. S., Olsen, P. D., ve Portas, M. D. (2007). The effect of static, ballistic, and proprioceptive neuromuscular facilitation stretching on vertical jump performance. Journal of Strength and Conditioning Research, 21(1), 223.

6. Eniseler, N., Çamlıyer, H. ve Göde, 0. (1996). Çeşitli lig seviyelerine ve bu liglerde futbol oynayan oyuncuların oynadıkları mevkilere göre $30 \mathrm{~m}$ mesafe içindeki sprint derecelerinin karşılaştırılması. Futbol Bilim ve Teknoloji Dergisi, 3(2), 3-8.

7. Faigenbaum, A. D., Bellucci, M., Bernieri, A., Bakker, B. ve Hoorens, K. (2005). Acute effects of different warm-up protocols on fitness performance in children. The Journal of Strength \& Conditioning Research, 19(2), 376-381.

8. Fletcher, I. M. (2010). The effect of different dynamic stretch velocities on jump performance. European Journal of Applied Physiology, 109(3), 491-498.

9. Fletcher, I. M. ve Anness, R. (2007). The acute effects of combined static and dynamic stretch protocols on fifty-meter sprint performance in track-and-field athletes. Journal of Strength \& Conditioning Research, 21(3), 784.

10. Fletcher, I. M. ve Jones, B. (2004). The effect of different warm-up stretch protocols on 20 meter sprint performance in trained rugby union players. The Journal of Strength \& Conditioning Research, 18(4), 885-888.

11. Fletcher, I. M. ve Monte-Colombo, M. M. (2010). An investigation into the effects of different warm-up modalities on specific motor skills related to soccer performance. The Journal of Strength \& Conditioning Research, 24(8), 2096-2101.

12. Gaitanos, G. C., Williams, C., Boobis, L. H. ve Brooks, S. (1993). Human muscle metabolism during intermittent maximal exercise. Journal of Applied Physiology, 75(2), 712-719.

13. Gharbi, Z., Dardouri, W., Haj-Sassi, R., Chamari, K. ve Souissi, N. (2015). Aerobic and anaerobic determinants of repeated sprint ability in team sports athletes. Biology of Sport, 32(3), 207.

14. Herbert, R. D. ve Gabriel, M. (2002). Effects of stretching before and after exercising on muscle soreness and risk of injury: systematic review. BMJ, 325(7362), 468.

15. Impellizzeri, F., Rampinini, E., Castagna, C., Bishop, D., Bravo, D. F., Tibaudi, A. ve Wisloff, U. (2008). Validity of a repeated-sprint test for football. International Journal of Sports Medicine, 29(11), 899-905.

16. Kafkas, M. E., İlbak, İ., Özgür, E., Çınarlı, F., Yılmaz, N. ve Kafkas, A. Ş. (2018). Farklı isınma protokollerinin 1-maksimum tekrar skuat performansı üzerine akut etkisi. Spor ve Performans Araştırmaları Dergisi, 9(3), 192-205.

17. Kokkonen, J., Nelson, A. G. ve Cornwell, A. (1998). Acute muscle stretching inhibits maximal strength performance. Research Quarterly for Exercise and Sport, 69(4), 411-415. 
18. Little, T. ve Williams, A. G. (2006). Suitability of soccer training drills for endurance training. Journal of Strength and Conditioning Research, 20(2), 316.

19. Manoel, M. E., Harris-Love, M. O., Danoff, J. V. ve Miller, T. A. (2008). Acute effects of static, dynamic, and proprioceptive neuromuscular facilitation stretching on muscle power in women. The Journal of Strength \& Conditioning Research, 22(5), 1528-1534.

20. Marinho, D. A., Gil, M. H., Marques, M. C., Barbosa, T. M. ve Neiva, H. P. (2017). Complementing warm-up with stretching routines: effects in sprint performance. Sports Medicine International Open, 1(3), E101.

21. Mohr, M., Krustrup, P. ve Bangsbo, J. (2003). Match performance of high-standard soccer players with special reference to development of fatigue. Journal of Sports Sciences, 21(7), 519528.

22. Mujika, I., Spencer, M., Santisteban, J., Goiriena, J. J. ve Bishop, D. (2009). Age-related differences in repeated-sprint ability in highly trained youth football players. Journal of Sports Sciences, 27(14), 1581-1590.

23. Nelson, A. G. ve Kokkonen, J. (2001). Acute ballistic muscle stretching inhibits maximal strength performance. Research Quarterly for Exercise and Sport, 72(4), 415-419.

24. Newman, M. A., Tarpenning, K. M. ve Marino, F. E. (2004). Relationships between isokinetic knee strength, single-sprint performance, and repeated-sprint ability in football players. Journal of Strength and Conditioning Research, 18(4), 867-872.

25. Özdemir, F. M., Yilmaz, A. ve Kin Isler, A. (2014). Genç futbolcularda tekrarlı sprint performansının yaşa göre incelenmesi. Spor Bilimleri Dergisi, 25(1), 1-10.

26. Pyne, D. B., Saunders, P. U., Montgomery, P. G., Hewitt, A. J. ve Sheehan, K. (2008). Relationships between repeated sprint testing, speed, and endurance. The Journal of Strength \& Conditioning Research, 22(5), 1633-1637.

27. Sekir, U., Arabaci, R., Akova, B. ve Kadagan, S. (2010). Acute effects of static and dynamic stretching on leg flexor and extensor isokinetic strength in elite women athletes. Scandinavian Journal of Medicine \& Science in Sports, 20(2), 268-281.

28. Shrier, I. ve Gossal, K. (2000). Myths and truths of stretching: individualized recommendations for healthy muscles. The Physician and Sportsmedicine, 28(8), 57-63.

29. Sim, A. Y., Dawson, B. T., Guelfi, K. J., Wallman, K. E. ve Young, W. B. (2009). Effects of static stretching in warm-up on repeated sprint performance. The Journal of Strength \& Conditioning Research, 23(7), 2155-2162.

30. Stølen, T., Chamari, K., Castagna, C. ve Wisløff, U. (2005). Physiology of soccer. Sports Medicine, 35(6), 501-536.

31. Taylor, J. M., Weston, M. ve Portas, M. D. (2013). The effect of a short practical warm-up protocol on repeated sprint performance. The Journal of Strength \& Conditioning Research, 27(7), 2034-2038.

32. Thompsen, A. G., Kackley, T., Palumbo, M. A. ve Faigenbaum, A. D. (2007). Acute effects of different warm-up protocols with and without a weighted vest on jumping performance in athletic women. Journal of Strength and Conditioning Research, 21(1), 52.

33. Turki-Belkhiria, L., Chaouachi, A., Turki, O., Chtourou, H., Chtara, M., Chamari, K., .. . Behm, D. G. (2014). Eight weeks of dynamic stretching during warm-ups improves jump power but not repeated or single sprint performance. European Journal of Sport Science, 14(1), 19-27.

34. Wadley, G. ve Le Rossignol, P. (1998). The relationship between repeated sprint ability and the aerobic and anaerobic energy systems. Journal of Science and Medicine in Sport, 1(2), 100110. 
35. Wong, D. P., Chaouachi, A., Lau, P. W. ve Behm, D. G. (2011). Short durations of static stretching when combined with dynamic stretching do not impair repeated sprints and agility. Journal of Sports Science \& Medicine, 10(2), 408.

36. Yamaguchi, T., Ishii, K., Yamanaka, M. ve Yasuda, K. (2007). Acute effects of dynamic stretching exercise on power output during concentric dynamic constant external resistance leg extension. J Strength Cond Res, 21(4), 1238-44.

37. Young, W. B. ve Behm, D. (2003). Effects of running, static stretching and practice jumps on explosive force production and jumping performance. Journal of Sports Medicine and Physical Fitness, 43(1), 21-27.

38. Zmijewski, P., Lipinska, P., Czajkowska, A., Mróz, A., Kapuściński, P. ve Mazurek, K. (2020). Acute effects of a static vs. a dynamic stretching warm-up on repeated-sprint performance in female handball players. Journal of Human Kinetics, 72(1), 161. 